\title{
Editorial: Special issue on engineering education
}

\author{
Asbjørn Rolstadås · Augusta Maria Paci
}

Published online: 10 May 2012

(C) Springer Science+Business Media, LLC 2012

On engineering education, thoughts flourished in recent years. Particularly in the European Union, these thoughts prospect for the twenty-first century new developments and expectations in this extremely important area of knowledge that plays a vital role in the economy and in the society of each advanced country. Highly qualified engineers, in particular in the large manufacturing industry, enable both market success and industrial innovation in the knowledge global economy.

For the purpose of preparing high skilled human resources in the field of engineering disciplines, the world of the scientific knowledge - universities, research centres, laboratories - and the world of the industrial knowledge - products, processes, organizations-investigate modes of education and training based on physical connections and knowledge interactions. The scope is to achieve people with a competence ready to match the capabilities needed to act in very dynamic jobs, contexts and opened to global developments.

Particularly, SMEs are assisted by internationalization networks that support and stimulate the multiple activities that surround the life of educated people that are used and appreciate the opening to the world as adding value to the respective culture.

This Special Issue on Engineering Education contains papers that highlight different initiatives all around and outside Europe within specialty fields. In the variety of national

A. Rolstadås ( $\square)$

Department of Production and Quality Engineering, Norwegian University of Science and Technology, 7491 Trondheim, Norway e-mail: Asbjorn.Rolstadas@ntnu.no

\footnotetext{
A. M. Paci

Department of Chemistry and Materials Technology, Consiglio Nazionale delleRicerche, Viale dell'Università, 11, 00185 Rome, Italy

e-mail: augustamaria.paci@cnr.it
}

settings with related efficient education systems, the aim is to address experiences of industry/academia collaboration that propose new models of preparing highly qualified engineers. The changing in industrial patterns is due to many reasons. The global crisis is accelerating the industrial transformation and the provision of next generation technologies is also concurring to change products, processes and organizations in the future industrial landscape. This unclear state of the industrial relations is complicated when knowledge development should be combined with future jobs. This complex theme is dealt with in the recently published final report by SEOR/Technopolis "Assessment of Impacts of NMP Technologies And Changing Industrial Patterns on Skills And Human Resources“. The report was prepared under contract to the European Commission, Directorate-General for Research and Innovation (DG RTD). This research report highlights aspects of a relation between push and pull innovation and the industrial transformation and confirm that companies are rather critical about the education system - mainly due to lack of cooperation. This is a challenge both to academia and industry that needs to be addressed in a constructive manner.

Engineering education and training for twenty-first century needs to develop capacities in the students in accordance with the determinants for innovation and to develop engineering competence enabling to apply aspects to reflect the incoming industrial era.

In order to offer an overview of the efforts spent in bringing new concepts into concrete and forward-looking initiatives, this Special Issue groups the papers into two sections: "Perspectives in capacity building" and "International cooperation for globalization".

The papers offer eleven profiles written by authors that report and summarize the new conception and intentions to develop into the students new factors in the engineering 
education to meet the needs of industries in the knowledge economy and to support the propensity to innovation as a steady state for new products, new processing and new enterprises.

The papers in the "Perspectives in capacity building" section deal with advanced education for engineers, models for ICT-based environment and approaches to competence developments for future skills and continuing education. These papers bring together experiences and thoughts of some European countries.

The section "International cooperation for globalization" contains papers dealing with needs for education of engineers touching the critical aspects in global manufacturing.

The all set of papers show that is needed a mutual understanding of competence and skills in order to develop high human potential for increasing long term knowledge-sharing. Through cooperation between different cultural settings, in particular for SMEs, strategic partnership exploits synergy between complementary competences of the participants.

In this perspective, European Commission "Europe 2020 Strategy"supports the 'Agenda for new skills and jobs' initiative and the 'Innovation Union' flagship initiatives through the Marie Curie programme. Stronger cooperation between universities and business via staff exchange will encourage entrepreneurship and help to turn creative ideas into innovative products and processes that can efficiently address European and global societal challenges.

During 2012, specific actions for industry-academia partnerships and pathways are planned to address the need of developing new working models of the 'knowledge triangle' whereby education, research and innovation are brought together in international and interdisciplinary networks to undertake joint research training and transfer of knowledge. These projects will represent a great opportunity to shape key skills which are equally relevant to the public and private sectors and that will impact positively on future employability. New stories and experiences will come out, hopefully moving a step forward from what we publish in this Special Issue.

The knowledge economy requires continuous learning. All types of learning are valuable, since it prepares people for "learning to learn". This means that engineering education must be delivered both on university campus and at the workplace. For those in industry seeking further education in combination with a job industry, education must be delivered at a time and place they can chose themselves.According to OCDE review programme on Higher Education in Regional and City development carried on in 2011, universities should also adopt a wider innovation concept that is not solely focus on science, helps increase the knowledge intensity of jobs, fosters product and process innovation, and aligns higher education provision with the needs and opportunities of regions and SMEs".

This Special Issue demonstrates that there are on the floor new models and options available to enable efficient learning for the manufacturing industry. In past years, the European Commission funded the special actions GEM and IMS 2020 that strongly recommended to strengthen the cooperation between higher education institutions and the industry, and this seems in place. In particular in the IMS 2020 action, nine research topics for improving engineering education were identified and the idea of launching this Special Issue came in this context.

We, the editors, are confident that this special issue with its research papers on engineering education with both an academic and industrial focus will push further this initial research and extend and consolidate the debate around mutual benefits from the cooperation between industry and academia in the globalized paths of the knowledge economy. 